\title{
Cardioprotective effects of garcinol following myocardial infarction in rats with isoproterenol-induced heart failure
}

\author{
Man Li', Xuewen Li and Lifeng Yang
}

\begin{abstract}
Myocardial infarction is a clinical form of necrosis in the myocardium caused by an imbalance between the coronary blood supply and myocardial demand. Garcinol is a polyisoprenylated benzophenone found in the fruit of Garcinia indica, which is abundant in tropical regions. This fruit contains high levels of garcinol, isoxanthochymol, isogarcinol, hydroxycitric acid and xanthochymol. Garcinol and hydroxycitric acid have been shown to have antioxidant effects. In this study, rats were assigned to sham, control, low-dose, high-dose and positive control groups. Hemodynamic and apoptotic markers were evaluated, and histopathological analysis was conducted. The mRNA and protein levels of caspase-3, Bax, Bcl-2 and cleaved caspase-3 were quantified. Garcinol treatment increased the heart rate and improved the maximum rate of increase in left-ventricle (LV) pressure $\left(+\mathrm{dp} / \mathrm{d} t_{\max }\right)$, maximum rate of decrease in LV pressure $\left(-\mathrm{d} p / \mathrm{d} t_{\max }\right)$, LV ejection fraction and LV systolic pressure in rats with induced heart failure. Garcinol treatment reversed body, liver and heart weight changes, resulting in returns to near-normal levels. In the garcinol treatment group, the number of broken fibers, extent of inflammatory cell infiltration and rate of apoptosis remained within normal ranges. Garcinol reduced the cross-sectional areas of cardiomyocytes, and reduced interstitial fibrosis to a normal level. The mRNA and protein levels of cleaved caspase-3, caspase-3 and Bax were reduced, whereas those of Bcl-2 were increased, following high-dose $(100 \mathrm{mg} / \mathrm{kg})$ garcinol treatment. These findings suggest that garcinol effectively prevents apoptosis in rats with isoproterenol-induced heart failure and in cardiac H9C2 cells.
\end{abstract}

Keywords: Garcinol, Digitalis, Apoptosis, Interstitial fibrosis, H9C2 cells

\section{Introduction}

Myocardial infarction is a clinical form of necrosis in the myocardium caused by an imbalance between the coronary blood supply and myocardial demand (Srikanth et al. 2009). Increased free radical production occurs under ischemic conditions (Lord et al. 2011), and reactive oxygen species play central roles in several cardiac and metabolic disorders (Panth et al. 2016). Isoproterenol is a synthetic catecholamine that induces stress in the myocardial muscles (Fan 2019). It has been shown to increase the rates of free radical production and lipid

\footnotetext{
*Correspondence: Iman62125@gmail.com
}

Department of Cardiology, Shanxi Bethune Hospital (Shanxi Academy of Medical Sciences), NO. 99 Longcheng Street, Taiyuan, Shanxi 030000, China peroxidation, which leads to further necrosis in myocardial muscles (Khalil et al. 2015). Zhang et al. (2008) reported that the damage to myocardial tissue caused by isoproterenol is irreversible.

The plant flavonoids and phenolic compounds provide defense against oxidative stress (Amjad and Shafighi 2013). Flavonoids act as excellent antioxidants due to their free radical scavenging activity and protect tissue against free radical mediated lipid peroxidation (Knekt et al. 2002). Shah et al. (2019) evaluated the cardioprotective effects of several plant-derived products. Garcinol is a well-known polyisoprenylated benzophenone found in the fruit of Garcinia indica, which is abundant in tropical regions (Zhao et al. 2018). This fruit contains high concentrations of garcinol, isoxanthochymol, isogarcinol, hydroxycitric acid and xanthochymol (Chattopadhyay 
and Kumar 2006). Garcinol and hydroxycitric acid are known to have antioxidant properties (Liao et al. 2005). Patel et al. (2015) reported the cardioprotective potential of Garcinia indica extract, based on a rat model of isoprenaline-induced myocardial injury. Garcinol is a good antioxidant present in Garcinia indica which has structural similarity to curcumin as it contains both phenolic hydroxyl groups and a $\beta$-diketone moiety (Singh et al. 2011). Sutar et al. (2012) have reported the free radical scavenging activity of garcinol. Various plant-derived compounds have been shown to have cardioprotective potential through antioxidant effects (Haleagrahara et al. 2011; Fathiazad et al. 2012). During heart failure, cardiomyocyte apoptosis leads to cardiomyopathy ( $\mathrm{Li}$ et al. 2014). We hypothesized that garcinol would exhibit protective potential in rats with isoproterenol-induced heart failure. This study was conducted to evaluate the cardioprotective effect of garcinol following myocardial infarction in rats with isoproterenol-induced heart failure.

\section{Materials and methods Materials}

Garcinol (G5173), isoproterenol (I6504), bovine serum albumin, Dulbecco's modified Eagle medium, dimethyl sulfoxide (DMSO) and fetal bovine serum were obtained from Sigma-Aldrich (Shanghai, China). H9C2 cardiac cells were obtained from the American Type Culture Collection (USA).

\section{Animals}

Male albino Wistar rats (180-210 g) were obtained from the Animal House of Shanxi Bethune Hospital, NO. 99Longcheng Street, Taiyuan 030000, Shanxi, China. They were kept in standard rat cages under a 12/12-h light/dark cycle and standard atmospheric conditions $\left(60 \% \pm 5 \%\right.$ relative humidity at $\left.25{ }^{\circ} \mathrm{C} \pm 0.5{ }^{\circ} \mathrm{C}\right)$. The rats were provided access to water and food ad libitum.

\section{Animal model}

Isoproterenol was used to induce heart failure in the rats. It was administered at $5 \mathrm{mg} / \mathrm{kg}$ for 7 consecutive days (Jing et al. 2015).

\section{Experimental groups}

The rats were assigned to sham, control, high-dose (100 mg/kg garcinol), low-dose $(10 \mathrm{mg} / \mathrm{kg}$ garcinol) and positive control $(0.0225 \mathrm{mg} / \mathrm{kg}$ digitalis) groups. Garcinol and digitalis were dissolved in DMSO, and the respective doses (total volume, $0.5 \mathrm{~mL}$ ) were administered orally for 30 consecutive days. $\mathrm{H} 9 \mathrm{C} 2$ cardiac cells were separated into normal control, control, high-dose $(100 \mathrm{mg} / \mathrm{L}$ digitalis), low-dose $(10 \mathrm{mg} / \mathrm{L}$ digitalis) and positive control
$(0.0225 \mathrm{mg} / \mathrm{L}$ digitalis) groups. The cells were treated for $48 \mathrm{~h}$.

Evaluation of hemodynamic markers and histopathological analysis

Hemodynamic parameters were assessed according to Yuan et al. (2012). The rats' heart rate (HR), left ventricular systolic pressure (LVSP), left ventricular ejection fraction (LVEF), maximum rate of increase in left ventricular $(\mathrm{LV})$ pressure $\left(+\mathrm{d} p / \mathrm{d} t_{\max }\right)$ and maximum rate of decrease in $L V$ pressure $\left(-\mathrm{d} p / \mathrm{d} t_{\max }\right)$ were measured.

Histopathological examination of heart tissues was performed according to Molh et al. (2008). The mounted heart tissue specimen was observed and was scored under light microscopy. For a semi-quantitative comparison of the structural changes, the abnormalities in the tissue sections were graded from $0 \%$ (normal structure) to $100 \%$ (severe pathological changes).

\section{TUNEL assay}

Terminal deoxynucleotidyl transferase dUTP nick end labeling (TUNEL) assays were conducted according to a previously described method (de Torres et al. 1997). The numbers of apoptotic cells in rat heart tissue and apoptotic cardiac $\mathrm{H} 9 \mathrm{C} 2$ cells were determined in six randomly selected samples each. Analysis of fluorescence intensity through ImageJ was described in the documentation section of ImageJ and can be found at the URL: https:// imagej.nih.gov/ij/docs/.

\section{Rt-pcr}

Total RNA was isolated from heart tissue homogenate and converted into cDNA. The mRNA levels of Bax, caspase- 3 and Bcl-2 were quantified using the $2^{-\Delta \Delta C T}$ method (Yu et al. 2015). The primers used for mRNA amplification are listed in Table 1.

\section{Western blot analysis}

Protein levels in heart tissue homogenate were measured. After the isolation of proteins in the lysate, non-specific proteins were blocked using 5\% non-fat milk powder. The membranes were incubated with primary antibodies for Bax (1:500 dilutions), caspase-3 (1:300 dilutions) and Bcl-2 (1:500 dilutions) for $12 \mathrm{~h}$, then washed carefully and treated with horseradish peroxidase-conjugated IgG antibodies for $60 \mathrm{~min}$. Protein levels of Bax, caspase-3 and $\mathrm{Bcl}-2$ were determined using western blot analysis (Zhang et al. 2012).

\section{Statistical analysis}

Values are reported as means \pm standard deviations. Analysis of variance was applied to the data, and Tukey's 
Table 1 List of primers used for the mRNA amplification of caspase-3, Bax, and Bcl-2

\begin{tabular}{lll}
\hline Markers & Sense primer & Anti-sense primer \\
\hline GAPDH & 5'-TCCCTCAAGATTGTCAGCAA-3' & 5'-AGATCCACAACGGATACATT-3' \\
Bax & 5'-TGG AGCTGCAGAGGATGATTG-3' & 5'-GAAGTTGCCGTCAGAAAACATG-3' \\
Caspase-3 & 5'-TTAATAAAGGTATCCATGGAGAACACT-3' & 5'-TTAGTGATAAAAATAGAGTTCTTTTGTGAG-3' \\
BCl-2 & 5'-CAC CCCTGG CAT CTT CTC CTT-3' & 5'-AGC GTC TTC AGA GAC AGC CAG-3' \\
\hline
\end{tabular}

Table 2 Effects of garcinol on hemodynamic markers and cardiac function in isoproterenol-treated rats

\begin{tabular}{|c|c|c|c|c|c|}
\hline Hemodynamic markers & Sham & Control & Low-dose & High-dose & Digitalis \\
\hline $\mathrm{SBP}(\mathrm{mmHg})$ & $99.2 \pm 10.1$ & $72.5 \pm 6.5^{*}$ & $77.8 \pm 5.1$ & $92.4 \pm 9.1^{\#}$ & $96.5 \pm 8.2^{\# \#}$ \\
\hline $\mathrm{DBP}(\mathrm{mmHg})$ & $59.1 \pm 5.2$ & $44.3 \pm 4.1^{*}$ & $46.2 \pm 4.2$ & $52.5 \pm 4.1^{\#}$ & $54.1 \pm 4.3^{\#}$ \\
\hline HR (beat/min) & $358.2 \pm 16.2$ & $296.1 \pm 12.2^{*}$ & $317.2 \pm 14.2$ & $351.3 \pm 14.1^{\#}$ & $355.2 \pm 15.4^{\# \#}$ \\
\hline$+\mathrm{LV} \mathrm{d} p / \mathrm{d} t_{\max }(\mathrm{mmHg} / \mathrm{s})$ & $7226.5 \pm 681.3$ & $3145.1 \pm 273.2^{* * *}$ & $3818.2 \pm 319.2^{\#}$ & $6915.2 \pm 510.2^{\# \#}$ & $6716.3 \pm 562.5^{\# \# \# ~}$ \\
\hline$-\mathrm{LV} \mathrm{d} p / \mathrm{d} t_{\max }(\mathrm{mmHg} / \mathrm{s})$ & $5581.5 \pm 511.3$ & $2811.4 \pm 191.2^{* * *}$ & $3443.1 \pm 241.5^{\#}$ & $5412.2 \pm 291.3^{\# \#}$ & $5113.2 \pm 325.6^{\# \# \#}$ \\
\hline LVSP & $126.5 \pm 11.5$ & $77.3 \pm 5.1^{*}$ & $91.4 \pm 4.6^{\#}$ & $119.8 \pm 7.1^{\# \#}$ & $117.2 \pm 8.1^{\# \# \#}$ \\
\hline LVEF & $75.3 \pm 5.1$ & $50.7 \pm 4.1^{*}$ & $59.4 \pm 3.8$ & $72.2 \pm 4.8^{\#}$ & $69.5 \pm 4.2^{\#}$ \\
\hline
\end{tabular}

$\pm \mathrm{LV}$ dp/dtmax: Maximal rates of increase and decrease of left-ventricle pressure development. Data are expressed as mean \pm SEM. $n=6$ in each group

$H R$ Heart rate, DBP Diastolic blood pressure, SBP Systolic blood pressure, LVSP Left ventricular systolic pressure, LVEF Left ventricular ejection fraction

${ }^{*} P<0.05$ vs group I

\# $P<0.05$

$\# \#<0.01$

\#\#\# $P<0.001$ vs group II

post hoc tests were used for comparisons. $P$ values $<0.05$ were considered to be significant.

\section{Results}

In this study, the effects of garcinol in rats with isoproterenol-induced heart failure were investigated. Hemodynamic markers were measured after 30 days of garcinol administration. Garcinol treatment improved the LV $+\mathrm{d} p / \mathrm{d} t_{\max }, \mathrm{LV}-\mathrm{d} p / \mathrm{d} t_{\max }$, LVEF and LVSP and increased the HR (all $P<0.05$; Table 2). Body, liver and heart weight changes differed between control and treated rats (all $P<0.05$; Table 3). Garcinol treatment reversed the weight changes, leading to returns to near-normal levels.

Sham-operated rats had normal myocardial cell nuclei and no broken myocardial fibers. A greater degree of inflammatory cell infiltration and broken myocardial fibers were observed in control rats. In the garcinol-treated and positive control groups, the degrees of inflammatory cell infiltration and numbers of broken myocardial fibers remained within the normal ranges (Fig. 1). The cardiomyocytes of control rats had increased cross-sectional areas, and garcinol treatment reduced these areas $(P<0.05$; Fig. $1 b)$. The extent of interstitial fibrosis was greater in control rats and lesser in the garcinol- and digitalis-treated groups (all $P<0.05$; Fig. 1c). More apoptosis was observed in control $\mathrm{H} 9 \mathrm{C} 2$ cardiac cells and control
Table 3 Effects of garcinol on heart and liver weight in isoproterenol-treated rats

\begin{tabular}{lllc}
\hline Treatment & Body weight $(\mathbf{g})$ & Heart $(\mathbf{g})$ & Liver $(\mathbf{g})$ \\
\hline Sham & $197.5 \pm 5.5$ & $0.62 \pm 0.10$ & $8.6 \pm 0.2$ \\
Control & $162.2 \pm 6.2^{*}$ & $0.74 \pm 0.07^{*}$ & $12.1 \pm 0.2^{*}$ \\
Low-dose & $171.3 \pm 5.1$ & $0.71 \pm 0.05$ & $11.5 \pm 0.2$ \\
High-dose & $185.2 \pm 5.4^{\#}$ & $0.65 \pm 0.04$ & $9.4 \pm 0.2^{\#}$ \\
Digitalis & $194.3 \pm 6.1^{\#}$ & $0.66 \pm 0.07^{\#}$ & $10.2 \pm 0.2^{\#}$ \\
\hline
\end{tabular}

Data are expressed as mean \pm standard deviations. $n=6$ in each group

${ }^{*} P<0.05$ vs group 1

\# $P<0.05$ vs group II

rats than in cells and rats treated with garcinol and digitalis (all $P<0.05$; Figs. 2a, b, 3a, b).

RT-PCR was used to quantify the mRNA levels of Bax, caspase-3, Bacl-2 and cleaved caspase-3. In the control rats, mRNA levels of Bax, caspase- 3 and cleaved caspase- 3 were increased by $160 \%, 120 \%$ and $120 \%$, respectively, whereas Bcl-2 mRNA expression was reduced by 58\% (all $P<0.05$; Fig. 4a). Garcinol treatment reversed these effects, leading to returns to near-normal mRNA levels. Western blotting showed increased protein levels of Bax (150\%), caspase-3 (110\%) and cleaved caspase-3 (110\%), and decreased Bcl-2 mRNA expression (47\%) in 

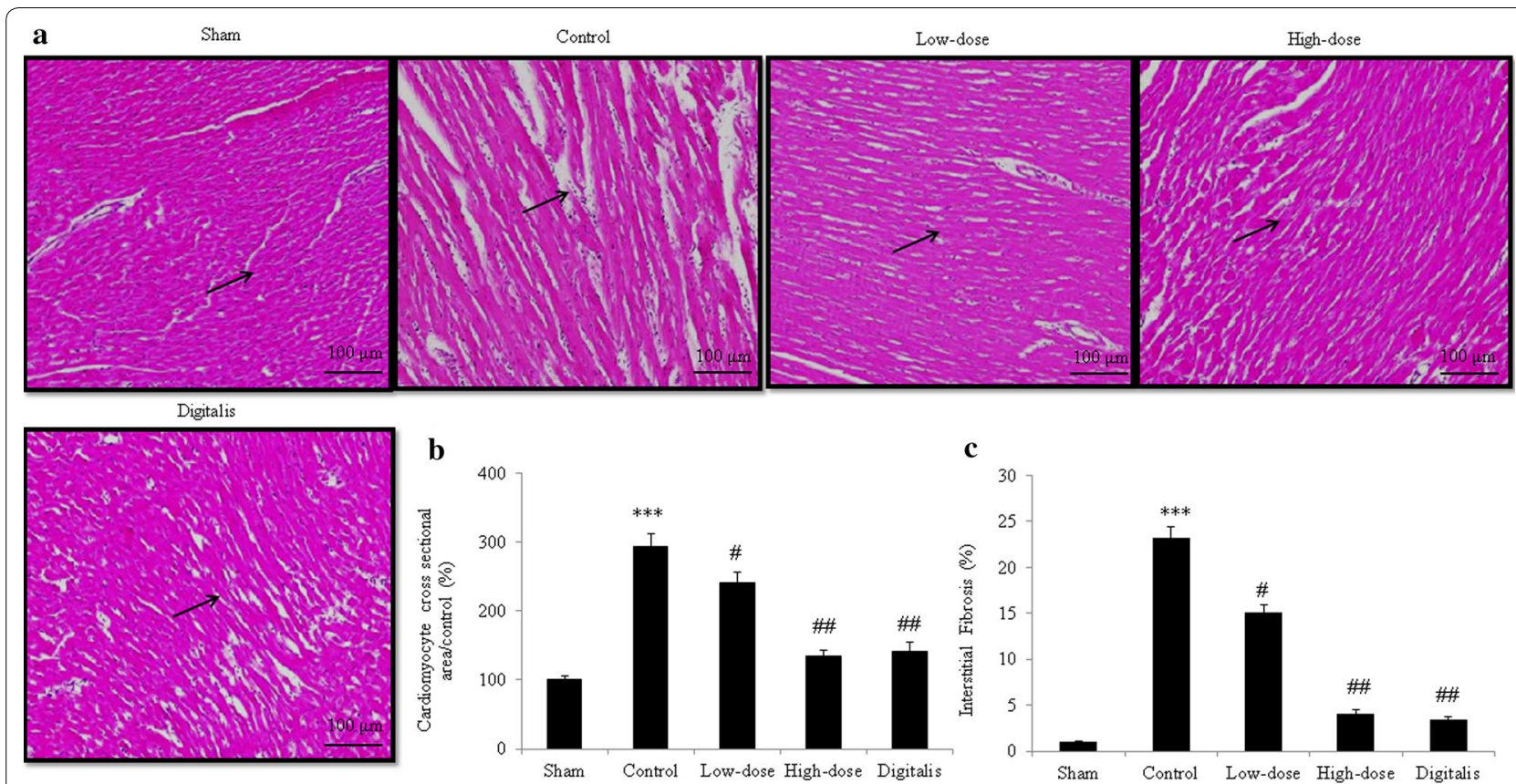

$* * * * 0<0.001,{ }^{*} P<0.05 \&{ }^{*} P<0.01$

Fig. 1 Histopathological evidence of the protective effects of garcinol in heart tissue from rats with isoproterenol-induced heart failure. a Microscopic view of rat heart tissue stained with hematoxylin and eosin. $\mathbf{b}$ Cardiomyocyte cross-sectional area. $\mathbf{c}$ Interstitial fibrosis. ${ }^{\#} P<0.05$, ${ }^{\#} P<0.01,{ }^{* * *} P<0.001$. Scale bar $=100 \mu \mathrm{m}$
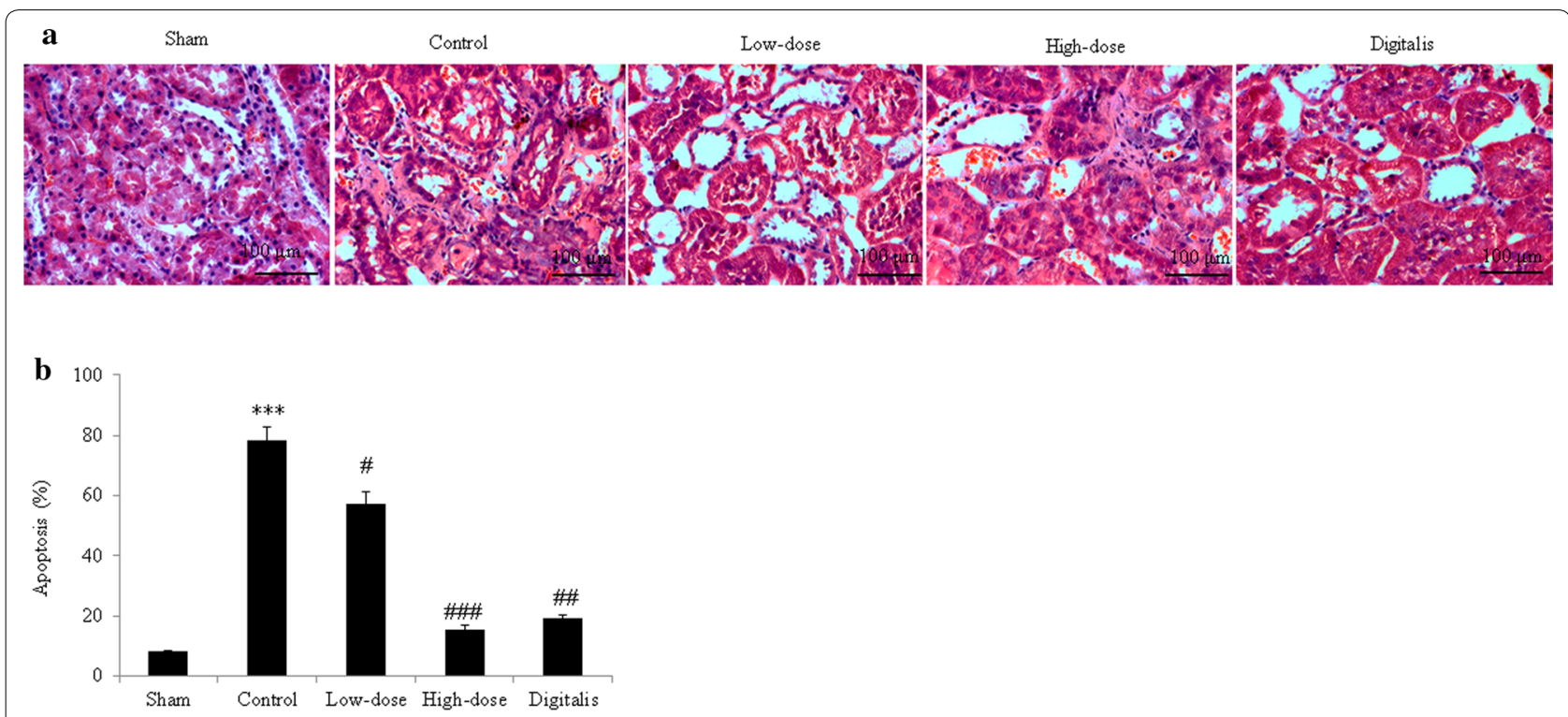

***: $P<0.001, \# P<0.05$, $p<0.01 \& * 0<0.001$

Fig. 2 Terminal transferase-mediated dUTP nick end labeling (TUNEL) assay results indicating the protective effects of garcinol against apoptosis in heart tissue from rats with isoproterenol-induced heart failure. a TUNEL images of rat heart tissue. $\mathbf{b}$ Percentages derived from (a). ${ }^{\#}<0.05$, ${ }^{\# \#} P<0.01,{ }^{\# \# \#} P<0.001,{ }^{* * *} P<0.001$. Scale bar $=100 \mu \mathrm{m}$ 

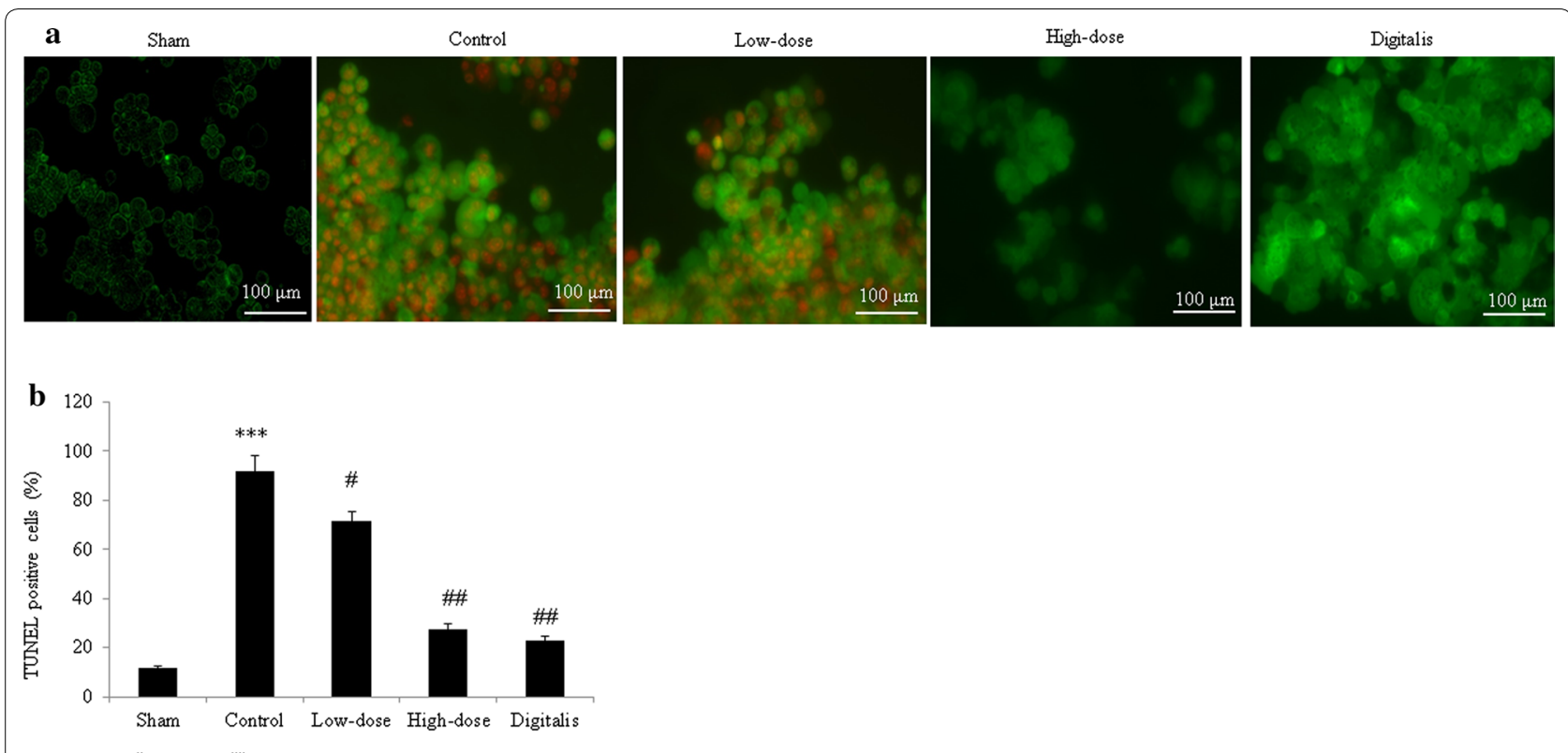

****: $P<0.001, " P<0.05 \& P<0.01$

Fig. 3 Terminal transferase-mediated dUTP nick end labeling (TUNEL) assay results indicating the protective effects of garcinol against apoptosis in isoproterenol-treated cardiac H9C2 cells. a TUNEL images of cardiac H9C2 cells. b Percentages derived from (a). ${ }^{\#} P<0.05,{ }^{\#} P<0.01,{ }^{\# \#} P<0.001$, ${ }^{* * *} P<0.001$. Scale bar $=100 \mu \mathrm{m}$

control rats (all $P<0.05$; Fig. 4b, c). Garcinol treatment reversed these changes, leading to returns to near-normal protein levels (all $P<0.05$; Fig. 4 b, c).

\section{Discussion}

This study investigated the therapeutic efficacy of garcinol in rats with isoproterenol-induced heart failure and cardiac H9C2 cells. Thanachartwet et al. (2016) described the key roles of several hemodynamic markers in cardiac function. The LV end diastolic pressure and $--\mathrm{d} p / \mathrm{d} t_{\max }$ reflect the degree of myocardial relaxation, whereas the LVSP and $+\mathrm{d} p / \mathrm{dt}_{\max }$ reflect the degree of myocardial contraction (Wang et al. 2017). In this study, garcinol treatment significantly increased the HR, LVSP, systolic blood pressure and diastolic blood pressure, and reduced the $\mathrm{LV}-\mathrm{d} p / \mathrm{d} t_{\max }$. The high dose of garcinol $(100 \mathrm{mg} /$ $\mathrm{kg})$ and positive control treatment $(0.0225 \mathrm{mg} / \mathrm{kg}$ digitalis) showed greater protective potential than did the low dose of garcinol $(10 \mathrm{mg} / \mathrm{kg})$, suggesting that garcinol had a positive inotropic effect in rats with isoproterenolinduced heart failure.

Cardiovascular risk factors, such as inflammation, dyslipidemia, metabolic syndrome and hypertension, are more prevalent in obese and overweight individuals (Lavie et al. 2013; Archer et al. 2013). Changes in body, liver and heart weight were measured in control and treated rats in this study. The garcinol treatment reversed such changes, restoring these weights to near-normal levels, suggesting that it can protect against excess weight gain. Histological examination of myocardial tissue is conducted to diagnose heart failure (Inamdar and Inamdar 2016). In this study, the occurrence of degenerative myocardial vacuoles, disordered arrangement of myocardial cells, fractured myocardial fibers, apoptosis and inflammatory cell infiltration was reduced significantly following garcinol treatment. These findings suggest that garcinol has protective effects on myocardial cells.

Shah et al. (2019) evaluated the cardioprotective effects of several plant-derived compounds. The fruit of the Garcinia indica plant is known to contain high levels of garcinol, isoxanthochymol, isogarcinol, hydroxycitric acid and xanthochymol (Chattopadhyay and Kumar 2006). Garcinol and hydroxycitric acid have been shown to have antioxidant effects (Liao et al. 2005). Patel et al. (2015) observed that Garcinia indica extract had cardioprotective potential in a rat model of isoprenaline-induced myocardial injury. In myocardial injury, caspase proteins are involved in the cascade leading to apoptosis (McIlwain et al. 2013; Snigdha et al. 2012). These results show that caspase- 3 plays an active role in apoptosis regulation in garcinol-treated rats.

In this study, garcinol treatment decreased the levels of cleaved caspase- 3 and caspase- 3 , indicating its inhibitory effect on apoptosis, in rats with isoproterenolinduced heart failure. Nakamura et al. (2000) reported 


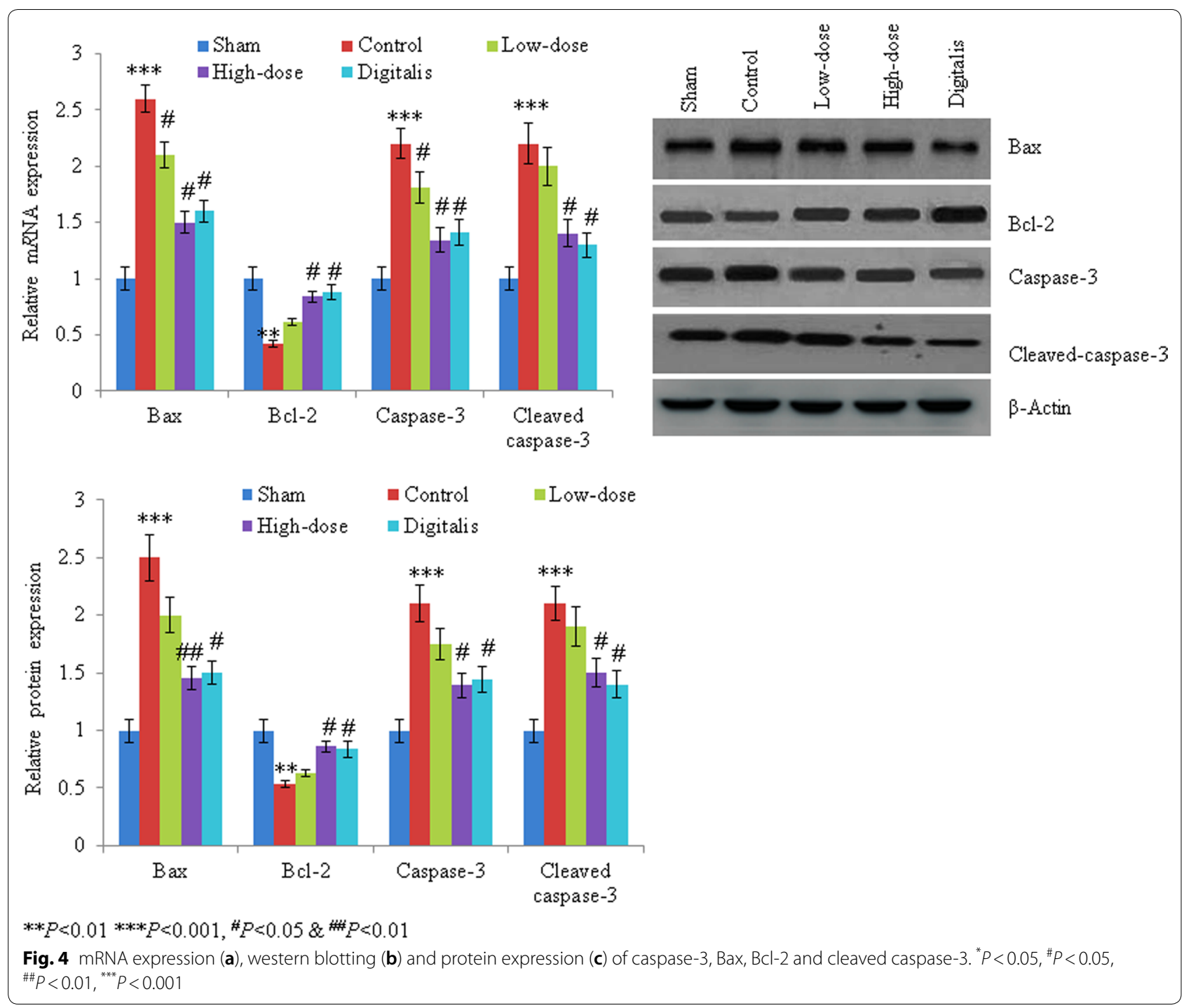

that $\mathrm{Bax} / \mathrm{Bcl}-2$ played an active role in the apoptosis cascade in cardiomyocytes. In this study, the protein expression of Bax was decreased and that of Bcl-2 was increased in heart tissue following garcinol treatment. Taken together, these findings suggest that garcinol protects against apoptosis in rats with isoproterenolinduced heart failure and in cardiac $\mathrm{H} 9 \mathrm{C} 2$ cells.

\section{Acknowledgements}

None.

\section{Authors' contributions}

ML and XL conducted experiments and collected data. LY carried out data interpretation, review of literature and manuscript drafting. All authors read and approved the final manuscript.

\section{Availability of data and materials}

Corresponding author could provide the all experimental data on valid request.

\section{Ethics approval and consent to participate}

All animal experiments were approved by the ethical committee of Shanxi Bethune Hospital ((No: 2020/2TX5226), NO. 99 Longcheng Street, Taiyuan 030000, Shanxi, China).

\section{Consent for publication}

Not applicable.

\section{Competing interests}

Authors declare that they have no conflict of interest.

Received: 18 June 2020 Accepted: 15 July 2020

Published online: 04 August 2020

Funding

None. 


\section{References}

Amjad L, Shafighi M (2013) Evaluation of antioxidant activity, phenolic and flavonoid content in Punica granatum var. Isfahan Malas flowers. Intl J Agri Crop Sci 5:1133-1339

Archer ER, Shook RP, Thomas DM (2013) 45-Year trends in women's use of time and household management energy expenditure. PLOS ONE 8:e56620

Chattopadhyay SK, Kumar S (2006) Identification and quantification of two biologically active polyisoprenylated benzophenones xanthochymol and isoxanthochymol in Garcinia species using liquid chromatographytandem mass spectrometry. J Chromatogr B Analyt Technol Biomed Life Sci 844:67-83

de Torres C, Munell F, Ferrer I, Reventós J, Macaya A (1997) Identification of necrotic cell death by the TUNEL assay in the hypoxic-ischemic neonatal rat brain. Neurosci Lett 230:1-4

Fan Y (2019) Cardioprotective Effect of Rhapontigenin in IsoproterenolInduced Myocardial Infarction in a Rat Model. Pharmacology 103:291-302

Fathiazad F, Matlobi A, Khorrami A, Hamedeyazdan S, Soraya H, Hammami M (2012) Phytochemical screening and evaluation of cardioprotective activity of ethanolic extract of Ocimum basilicum L. (basil)against isoproterenol induced myocardial infarction in rats. Daru 20, 87

Haleagrahara N, Varkkey J, Chakravarthi S (2011) Cardioprotective effects of glycyrrhizic acid against isoproterenol-induced myocardial ischemia in rats. Int J Mol Sci 12:7100-7171

Inamdar AA, Inamdar AC (2016) Heart Failure: diagnosis, management and utilization. J Clin Med 5(7):62

Jędrych M, Wawryk-Gawda E, Jodłowska-Jędrych B, Chylińska-Wrzos P, Jasiński $L$ (2013) Immunohistochemical evaluation of cell proliferation and apoptosis markers in ovarian surface epithelial cells of cladribine-treated rats. Protoplasma 250:1025-1034

Jing L, Wang Y, Zhao XM, Zhao B, Han JJ, Qin SC, Sun XJ (2015) Cardioprotective effect of hydrogen-rich saline on isoproterenol-induced myocardial infarction in rats. Heart Lung Circ 24:602-610

Khalil Ml, Ahmmed I, Ahmed R (2015) Amelioration of isoproterenol-induced oxidative damage in rat myocardium by Withania somnifera Leaf Extract. Biomed Res Int 2015:624159

Knekt P, Kumpulainen J, Järvinen R, Rissanen H, Heliövaara M, Reunanen A (2002) Flavonoid intake and risk of chronic diseases. Am J Clin Nutr 76:560-568

Lavie CJ, Alpert MA, Arena R, Mehra MR, Milani RV, Ventura HO (2013) Impact of obesity and the obesity paradox on prevalence and prognosis in heart failure. J Am Coll Cardiol HF 1:93-102

Li Y, Song P, Zhu Q (2014) Liguzinediol improved the heart function and inhibited myocardial cell apoptosis in rats with heart failure. Acta Pharmacol $\sin 35: 1257-1264$

Liao CH, Ho CT, Lin JK (2005) Effects of garcinol on free radical generation and $\mathrm{NO}$ production in embryonic rat cortical neurons and astrocytes. Biochem Biophys Res Commun 329:1306-1314

Lord K, Moll D, Lindsey JK (2011) Environmentally persistent free radicals decrease cardiac function before and after ischemia/reperfusion injury in vivo. J Recept Signal Transduct Res 31(2):157-167

Mcllwain DR, Berger T, MakTW (2013) Caspase functions in cell death and disease. Cold Spring Harb Perspect Biol 5(4):a008656

Molh AK, Ting LC, Khan J, Al-Jashamy K, Jaafar H, Islam MN (2008) Histopathological studies of cardiac lesions after an acute high dose administration of methamphetamine. Malays J Med Sci 15:23-30
Nakamura K, Bossy-Wetzel E, Burns K, Fadel MP, Lozyk M, Goping IS, Opas M, Bleackley RC, Green DR, Michalak M (2000) Changes in endoplasmic reticulum luminal environment affect cell sensitivity to apoptosis. J Cell Biol 150(4):731-740

Panth N, Paudel KR, Parajuli K (2016) Reactive oxygen species: a key hallmark of cardiovascular disease. Adv Med 2016:9152732

Patel KJ, Panchasara AK, Barvaliya MJ (2015) Evaluation of cardioprotective effect of aqueous extract of Garcinia indica Linn. fruit rinds on isoprenaline-induced myocardial injury in Wistar albino rats. Res Pharm Sci 10:388-396

Shah SMA, Akram M, Riaz M, Munir N, Rasool G (2019) Cardioprotective potential of plant-derived molecules: a scientific and medicinal approach. Dose Response 17(2):1559325819852243

Singh T, Kasture SB, Mohanty PK, Jaliwala Y, Karchuli M (2011) In vitro antioxidative activity of phenolic and flavonoid compounds extracted from fruit of Garcinia indica. Int J Pharm Lif Sci 2:613-616

Snigdha S, Smith ED, Prieto GA, Cotman CW (2012) Caspase-3 activation as a bifurcation point between plasticity and cell death. Neurosci Bull 28(1):4-24

Srikanth G, Prakash P, Tripathy N, Dikshit M, Nityanand S (2009) Establishment of a rat model of myocardial infarction with a high survival rate: a suitable model for evaluation of efficacy of stem cell therapy. J Stem Cells Regen Med 5(1):30-36

Sutar RL, Mane SP, Ghosh JS (2012) Antimicrobial activity of extracts of dried kokum (Garcinia indica C). Int Food Res J 19:1207-1210

Thanachartwet V, Wattanathum A, Sahassananda D (2016) Dynamic measurement of hemodynamic parameters and cardiac preload in adults with dengue: a prospective observational study. PLoS ONE 11:e0156135

Wang HJ, Rozanski GJ, Zucker IH (2017) Cardiac sympathetic afferent reflex control of cardiac function in normal and chronic heart failure states. J Physiol 595:2519-2534

Yu B, Zhang B, Zhou WB (2015) Assessing apoptosis gene expression profiling with a PCR array in the hippocampus of Ts65Dn mice. Biomed Res Int 2015:214618

Yuan Y, Wang X, Zeng Q, Wu HM, Qi YF, Tang CS (2012) Effects of continuous intermedin infusion on blood pressure and hemodynamic function in spontaneously hypertensive rats. J Geriatr Cardiol 9:17-27

Zhang J, Knapton A, Lipshultz SE, Weaver JL, Herman EH (2008) Isoproterenolinduced cardiotoxicity in sprague-dawley rats: correlation of reversible and irreversible myocardial injury with release of cardiac troponin $T$ and roles of iNOS in myocardial injury. Toxicol Pathol 36(2):277-278

Zhang $H$, Xu F, Xie T, Jin H, Shi L (2012) $\beta$-elemene induces glioma cell apoptosis by downregulating survivin and its interaction with hepatitis $B$ X-interacting protein. Oncol Rep 28(6):2083-2090

Zhao J, Yang T, Ji J, Li C, Li Z, Li L (2018) Garcinol exerts anti-cancer effect in human cervical cancer cells through upregulation of T-cadherin. Biomed Pharmacother 107:957-966

\section{Publisher's Note}

Springer Nature remains neutral with regard to jurisdictional claims in published maps and institutional affiliations.

\section{Submit your manuscript to a SpringerOpen ${ }^{\circ}$ journal and benefit from:}

- Convenient online submission

- Rigorous peer review

- Open access: articles freely available online

- High visibility within the field

- Retaining the copyright to your article

Submit your next manuscript at $\boldsymbol{\nabla}$ springeropen.com 